\title{
Distribuiçào do sedimento do leito do rio Amazonas - nenhuma mudança apreciável rio abaixo
}

\author{
Carl F. Nordín, Jr. ('), Robert H. Meade ('), William F. Curtis (1), Nivaldo J. Bósio $\left({ }^{2}\right)$ \\ e Paulo M. B. Landim $\left({ }^{2}\right)$
}

\begin{abstract}
Resumo
Neste trabalho é estudada a distribuição de tamanho cias partículas do leito do rio Amazonas, que não mostrou variação apreciável desde Iquitos, no Peru, até Macapá, no Brasil, nume distância de $3.200 \mathrm{~km}$.
\end{abstract}

As primeiras observaçōes registradas do sedimento do leito do rio Amazonas foram fuitas em 1843 pelo Tenente Wiiliam Lewis Herndon, da Marinha dos Estados Unidos, quanclo navegou o rio de suas cabєceiras até sua boca, sondando suas profundidades e anotando a natureza das partículas coletadas em um peso de sondagem com muita graxa no fundo (Herndon, 1853). Ele registrou que o material do leito do rio era na maioria areia e finos cascalhos. Oitman e Ames coletaram em umas poucas localidades em 1963 e 1964, e registraram que o material do leito em Óbidos, Brasil, eram pequenas areias, com diâmetro médio variando de 0,15 até $0,25 \mathrm{~mm}$ (Oiiman, 1968). Neste trabalho apresentamos um sumário da análise de tamanho de partículas d: amostras de material do leito do rio coletacio do rio Amazonas e de seus principais tribu'ários ao longo de uma extensão do rio de Iqui:tos, no Peru, cerca de $3.500 \mathrm{~km}$ acima de Mzcapá, Brasil, até um ponto $220 \mathrm{~km}$ acima d: Macapá (Nordiv et al., 1977, 1979) .

O trabalho de campo foi feito a bordo do Navio de Pesquisa "Alpha Helix". As amostres eram coletadas com dragas de tubo (Norcin et al., 1977), ou com um coletor de matorial do leito U.S. BM-54 (Inter-Agency Committes, 1963), secado a bordo do navio, e transportado para os iaboratórios da U.S. Geological Survey em Denver, Colorado, para análise do tamanhs da partícula por peneiramento, ou por métodos do tubo de acumulação pipeta-visual (Guy 1969).

As observaçōes do Tenente Herndon foram notavelmente corretas; o leito do Amazonas é principalmente areia fina. Muitas de noss:s emostras continham pequenas percentagens dc pequenos cascalhos; estes eram especialmente dominantes em lugares onde havia afloramentos locais nos terraços adjacentes, ou onde as condições favoreciam seleção hidráulica pcr completo no lado externo das curvas, abaixo das confluências com alguns dos principais tri. butários, onde existem zonas de alta "shearing" tanto no fluxo como no leito com turbulência excepcionalmente alta, ou em secções muito estreitas com altas velocidades. A Fig. 1 mos tra uma comparação de distribuições do tamenho da partícula do material coletado em um profundo buraco logo abaixo da confluência do rio Negro e rio Solimões, e de material colctado $131 \mathrm{~km}$ acima e $74 \mathrm{~km}$ abaixo da confluência. As impressionantes diferenças na distribuição por tamanho aparentemente são devidao à seleção hidráulica na confluência em combinação com afloramentos de pequenos casce. Ihos na formação de Alter do Chão.

$\mathrm{Na}$ maioria dos cursos d'água aluvianos, o material do leito torna-se mais fino e mais uniforme, rio abaixo. A Fig. 2a, por exempl: mostra a tendência de diminuição do tamanho da partícula para o material do leito do rio Mississipi ao longo de uma distância de $1.600 \mathrm{~km}$ abaixo de Ca:ro, Illinois (U.S. Wateiways Experiment Station, 1935). O diâmetro médio da partícula ao longo da extensão é reduzido de cerca de 0.7 para $0,2 \mathrm{~mm}$.

(1) - U.S. Geological Survey - Denver, Colorado 80225.

(2) - Universidac'e Estadual Paulicta - Pio Claro, Sảo peulo 


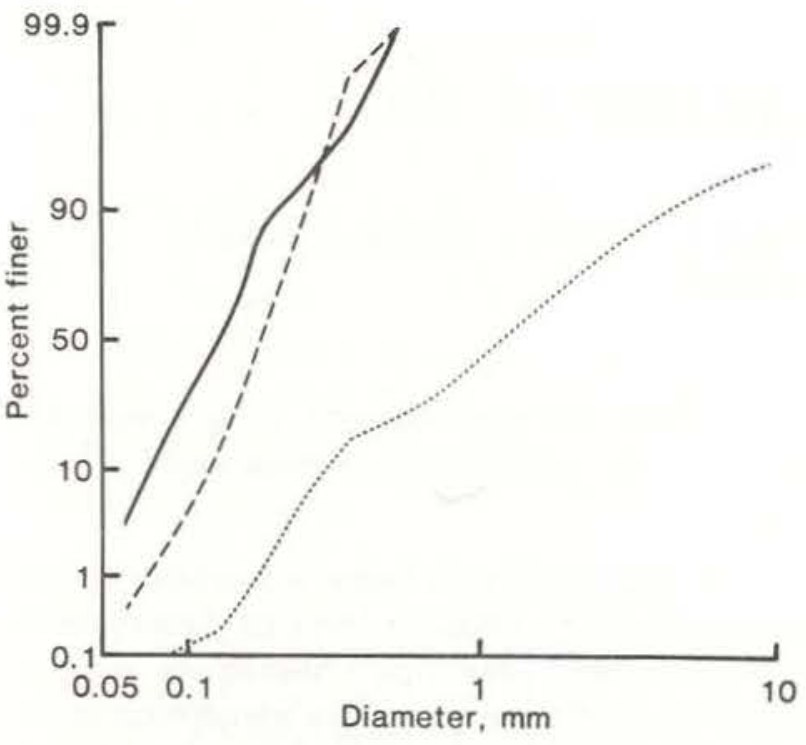

Fig. 1 - Seleçāo hidráulica na confluência dos rios Negro e Solimões resulta nos depósitos locais de cascalho. A profundidade da água era $54 \mathrm{~m}$. As curvas estăo codificadas como se segue : ............ confluência do rio Negro e rio Solimões: $-\ldots \ldots$, rio Amazonas, $74 \mathrm{~km}$ abaixo da confluência; —— rio Solimōes, $131 \mathrm{~km}$ acima da confluência.

Uma redução tão notável, no tamanho da partícula, não foi encontrada para o rio Amazonas entre Iquitos e Belém. Uma plotagem dos diâmetros médios do material do leito de nossas 1977 amostras contra a distância rio abaixo de lquitos (Fig. 2b) não mostra tendência significativas. Para eliminar os efeitos de seleção hidráulica local, sistematicamente, coletamos algumas de nossas amostras em passagens entre curvas. Quando estes dados são plotados (Fig. 2b), uma teve tendência na direçäo da diminuição do tamanho da partícula aperente

Em várias secções transversais onde medimos a descarga de sedimento em suspensão (Meade et al., 1979a, b), coletamos cinco ou mais amostras do leito em intervalos igualmente espaçados através das secções. As curvas médias (Fig. 3) não mostram diferenças apreciáveis nas distribuições do tamanho da partícula. Variação através do canal no tamanho da partícula em várias secções transversais foi pelo menos tão grande como variações, rio abaixo encontradas ao longo da extensão total de $3.300 \mathrm{~km}$.
Um coeficiente de seleção, $\sigma$, foi encontrado para cada amostra:

$$
\sigma=1 / 2\left(\frac{d_{50}}{d}+\frac{d}{d 6}+\frac{84}{d 50}\right) .
$$

onde o subscrito representa a porcentagem menor. Por exemplo, $d_{50}$ é o tamanho da partícula para o qual $50 \%$ por peso é menor. Valores de $\sigma$ variaram de 1,18 até 2,59 , com $70 \%$ dos valores caindo entre 1,20 e 1,40; o valor mais alto, 2,59, foi para a amostra coletada na confluência do rio Negro e rio Solimões, cuja distribuição de tamanho está mostrada na Fig. 1. Quando os valores de $\sigma$ foram plotados contra distância, nenhuma tendência significa-
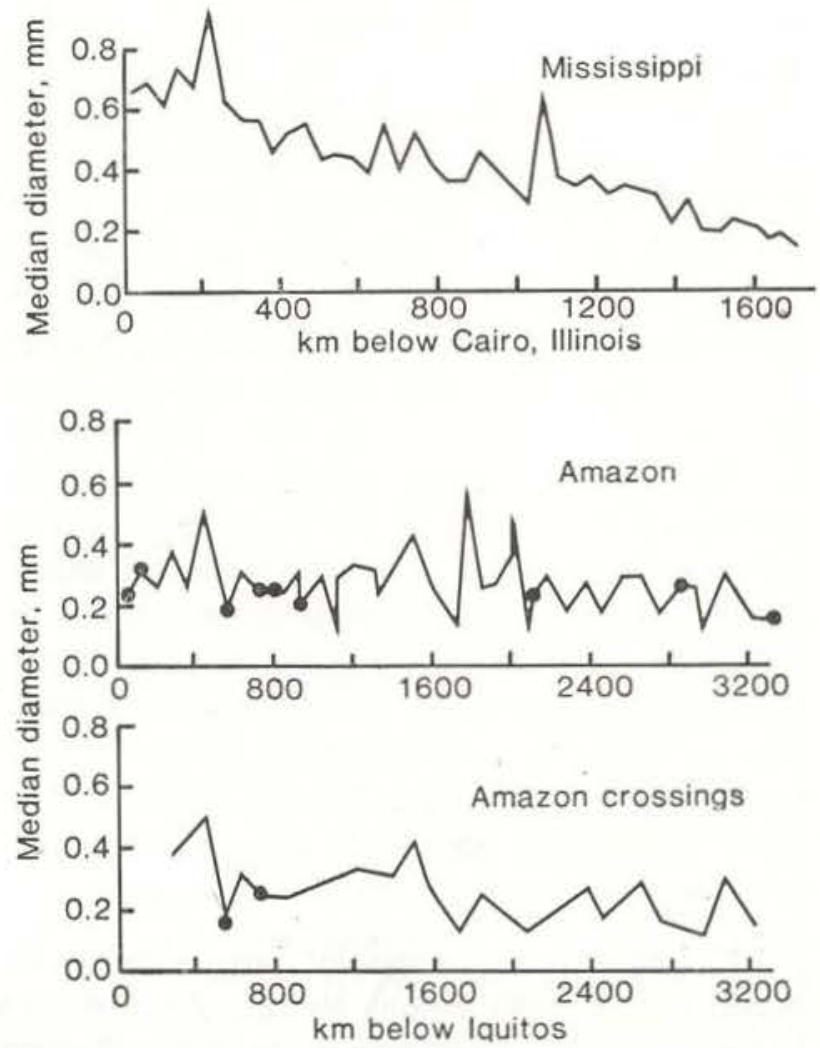

Fig. 2 - Variação com a distância do tamanho médio das partículas (a) para o rio Mississipi; (b) para o rio Amazonas. Os tamanhos médios apresentados para o Mississipi são médios de areias (diâmetro médio 0,06 até $2,00 \mathrm{~mm}$ ) para extensōes de $40 \mathrm{~km}$ do rio. Tamanhos médios apresentados para o Amazonas são principalmente amostras individuais; os círculos escuros são valores médios onde duas ou mais amostras foram coletadas em uma secçāo transversal. 


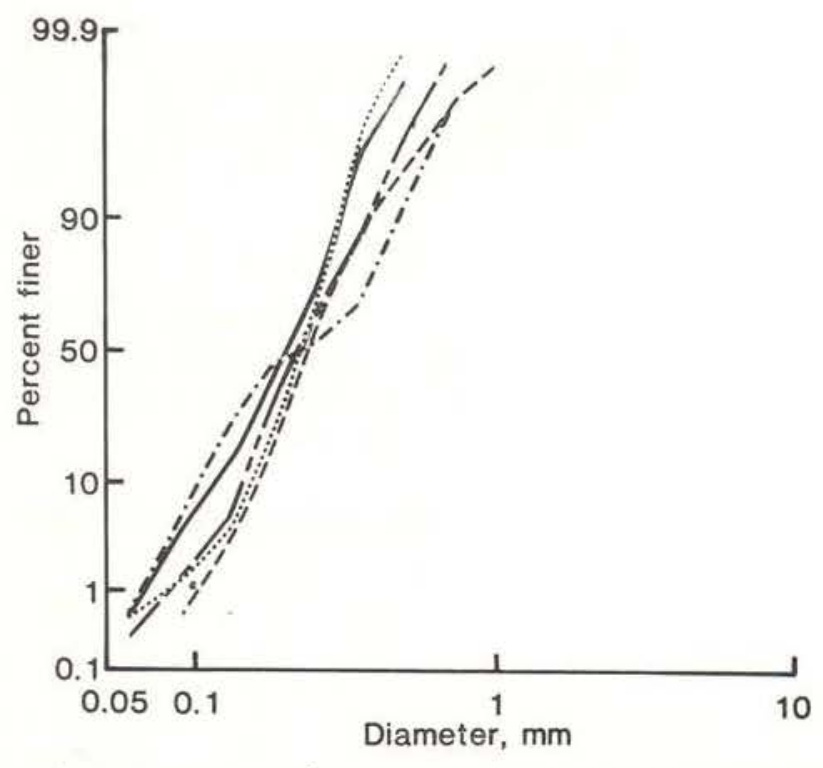

Fig. 3 - Curva de distribuição do tamanho médio das partículas para secçōes transversais onde 5 ou mais amostras foram coletadas. As curvas estão codificadas como se sugere : — $-\longrightarrow$, rio Maranőn, $25 \mathrm{~km}$ abaixo de Iquitos; $\ldots \ldots \ldots$, rio Solimões em São Paulo de Olivença, $757 \mathrm{~km}$ abaixo de Iquitos; - rio Solimões próximo de Santo Antônio do Içá, $909 \mathrm{~km}$ abaixo de Iquitos; ._._...., rio Solimões em Manacapuru, $2.827 \mathrm{~km}$ abaixo de lquitos.

tiva foi encontrada. O material do leito não tende a ficar mais uniforme rio abaixo. como ocorre na maioria dos outros cursos d'água aluvianos.

Embora o tamanho médio e o tipo das areias no leito do Amazonas sejam essencialmente constantes na extensão de $3.300 \mathrm{~km}$ que amostramos, a composição das areias na mesma extensão muda significativamente. Para um oiho nu, as areias coletadas próximo a Iquitos mostram-se mais escuras que as coletadas mais abaixo no rio, face a uma maior proporção de grãos minerais escuros e fragmentos de rochas. Os conjuntos de minerais pesados também diferem.

Landim et al. (1978) registram que as areias nos primeiros $1.300 \mathrm{~km}$ ou, aproximadamente, abaixo de lquitos, são ricas em minerais instáveis, tais como "hypersthene", augite e anfibólio; estes indicam uma fonte predominantemente andina. As areias nos $2.000 \mathrm{~km}$ inferiores contêm menos minerais instáveis e maiores proporções de zircão e turmalina. Se esta mudança na composição mineral representa a decomposição progressiva de minerais instáveis dos Andes, durante o transporte ou durante a estocagem temporária nos depósitos aluvianos, ou se representa diluição de material andino até areia das áreas do escudo Precambriano ao norte e sul do Amazonas, permanece para ser determinada. Em qualquer caso, mudanças na composição mineral não são acompanhadas por quualquer mudança perceptível no tamanho da partícula, rio abaixo.

\section{SUMMARY}

Samples of bed material from the Amazon River along a $3200 \mathrm{~km}$ reach between in Peru and Macapá in Brazil show no appreciable change in particle size distribution.

\section{REFERENCIAS BIBLIOGRÁFICAS}

GUY, H.P.

1969 - Laboratory thoery and methods for sediment analysis: Techniques of water-resources investigations of the United States Geological Survey. Book 5, Chapter C1, 58p.

HERNDON, L.T.W.L.

1853 - Exploration of the valley of the Amazon made under direction of the Navy Department, Part 1: U.S. Senate Executive Document No. 36, 32nd Congress, 2nd Session.

INTER-AGENCY COMMITTEE ON WATER RESOURCES

1963 - Determination of fluvial sediment discharge: Report No. 14, U.S. Government Printing Office, 151p.

LANDIM, P.M.B.; BOSIO, N.J.; WV, F.T.; MEYER, A.E. Jr.; CASTRO, P.R.M.

1978 - Heavy minerals from Amazon River bed: ES, 59 (4), 227.

MEADE, R.H.; NORDIN, C.F., Jr.; CURTIS, W.F.;

MAHONEY, H.A.; DELANEY, B.M.

1979a - Suspended-sediment and velocity data, Ama. zon River and its tributaries, June-July 1976 and May-June 1977: U.S. Geological Survey Open-File Report 79-515, 42p.

MEADE, R.H.; NORDIN, C.F. Jr.; CURTIS, W.F.; RODRIGUEZ, F.M.; DO VALE, C.M.

1979b- Sediment loads in the Amazon River: Nature, 278 (5700) 161-163 
NORDIN, C.F. Jr; MEADE, R.H.; MAHONEY, H.A. DELANEY, B.M.

1977 - Particle size of sediments collected from the bed of the Amazon River and its tributaries in June and July 1976. U.S. Geological Survey Open-File Report 77-400, 18p.

NORDIN, C.F. Jr.; MEADE, R.H.; CURTIS, W.F.; BOSIO, N.J.; DELANEY, B.M.

1979 - Particle sizes of sediments collected from the bed of the Amazon River and its tributaries in May and June 1977. U.S. Geological Survey Open-File Report 79-329, 23p.
OLTMAN, R.E.

1968 - Reconnaissance investigations of the discharge and water quality of the Amazon River. U.S. Geological Survey Circular 522, 16p.

\section{U.S. WATERWAYS EXPERIMENT STATION}

1935 - Studies of river bed materials and their movement with special reference to the lower Mississippi River. U.S. Army Corps of Engineers, Paper 17, 161p.

(Aceito para publicação em 17/07/80) 